\title{
PLAZOS DE LAS MEDIDAS CORRECTORAS EN CASO DE VICIOS OCULTOS SEGÚN LA DIRECTIVA (UE) 2019/770 SOBRE CONTRATOS DE SUMINISTRO DE CONTENIDOS Y SERVICIOS DIGITALES Y LA DIRECTIVA (UE) 2019/771 SOBRE EL CONTRATO DE COMPRAVENTA DE BIENES*
}

\section{TIME LIMITS OF REMEDIES FOR HIDDEN DEFECTS UNDER UNDER DIRECTIVE (EU) 2019/770 ON CONTRACTS FOR THE SUPPLY OF DIGITAL CONTENT AND DIGITAL SERVICES AND DIRECTIVE (EU) 2019/771 ON CONTRACTS FOR THE SALE OF GOODS}

\author{
Prof $^{\mathrm{a}}$. DR ${ }^{\mathrm{a}}$. BeAte GSELL \\ Catedrática de Derecho Privado, Derecho Procesal Civil y Derecho Privado \\ y Procesal Europeo \\ Ludwig-Maximilians-Universität Munich \\ Rodrigo Araldi, LL. M. (Munich) \\ Doctorando y asistente de investigación en la Cátedra de Derecho Privado, Derecho \\ Procesal Civil y Derecho Privado y Procesal Europeo \\ Ludwig-Maximilians-Universität Munich
}

Recibido: 16.06.2020 / Aceptado: 01.07.2020

DOI: https://doi.org/10.20318/cdt.2020.5617

\begin{abstract}
Resumen: En el presente estudio se aborda la cuestión de los plazos para el ejercicio efectivo de remedios por falta de conformidad en los contratos de compraventa y suministro de contenidos y servicios digitales con arreglo a las Directivas 2019/770 y 2019/771. En particular, se examinan los plazos aplicables en caso de vicios ocultos, que sólo se manifiestan después de la entrega de los bienes o del suministro del contenido digital. Además, se ocupa de la situación más compleja de los vicios ocultos en los contratos que prevén el suministro continuo del contenido digital. La finalidad es evaluar tanto la adecuación de la solución legislativa adoptada en cada Directiva como la coherencia entre ambas en cuanto al régimen jurídico aplicable a esos plazos.
\end{abstract}

Palabras clave: Derechos del consumidor, vicios ocultos, contratos de suministro de contenidos y servicios digitales, compraventa de bienes de consumo, plazo para ejercicio de las medidas correctoras.

*Este artículo es una versión ampliada en español del artículo de B. GSELL, "Time limits of remedies under Directives (EU) 2019/770 and (EU) 2019/771 with particular regard to hidden defects", en E. ARROYO AMAYUELAS - S. CÁMARA LAPUENTE (Coords.), El Derecho Privado en el nuevo paradigma digital, Madrid/Barcelona, Marcial Pons, 2020, que es un resultado del proyecto de investigación DER2017-84748-R, financiado por el Ministerio de Ciencia e Innovación de España y coordinado por el Prof. S. CÁMARA LAPUENTE. 
Abstract: This paper addresses the issue of time limits for the effective exercise of remedies for lack of conformity in consumer sales contracts and contracts for the supply of digital content and digital services under the new Directives 2019/770 and 2019/771. In particular, it examines the time limits applicable in case of hidden defects, which only become apparent after the delivery of the goods or the supply of the digital content. It also addresses the more complex situation where such hidden defects exist in the context of contracts providing for a continuous supply over a period of time. The purpose of this article is to assess both the appropriateness of the legislative approach adopted in each directive and the coherence between the two directives as to the legal framework applicable to such time limits.

Keywords: consumer law, hidden defects, contracts for the supply of digital content and digital services, consumer sales contracts, time limits for the exercise of remedies.

Sumario: I. Introducción - II. Breves consideraciones sobre la delimitación del ámbito de aplicación objetivo de las directivas - III. Alcance de la plena armonización con respecto a los defectos ocultos. 1. Adopción del principio de armonización plena por ambas directivas. 2. Posibilidad de adopción de medidas correctoras nacionales adicionales con plazos nacionales específicos según la Dir (UE) 2019/771. 3. ¿Posibilidad de medidas correctoras nacionales adicionales con plazos nacionales específicos también según la Directiva (UE) 2019/770? - IV. Plazos de responsabilidad. 1. Directiva de Compraventa de Bienes (UE) 2019/771 A) Bienes B) Bienes con elementos digitales incorporados a) Plazo de responsabilidad distinto con respecto al suministro continuo de contenidos o servicios digitales b) Ausencia de un plazo para que el defecto oculto que se haya "producido" a tiempo se vuelva aparente. 2. Directiva de Contenidos y Servicios Digitales (UE) 2019/770 A) Un solo acto de suministro o una serie de actos individuales de suministro B) Suministro continuo a lo largo de un período de tiempo. 3. Resumen - V. Plazos de prescripción. 1. Bienes y bienes con elementos digitales incorporados en la Directiva de Compraventa A) Combinación del período de responsabilidad y del plazo de prescripción B) Plazo de prescripción sin adopción de un período de responsabilidad C) Bienes con elementos digitales que deban suministrarse de forma continua 2. Directiva de Contenidos Digitales A) Contenidos o servicios digitales que deban suministrase en un solo acto o en una serie de actos individuales B) Contenidos o servicios digitales que deben suministrarse de forma continua 3. Resumen - VI. Obligación de informar - VII. Carga de la prueba - VIII. Conclusión

\section{Introducción}

1. El 22 de mayo de 2019 se publicaron en el Diario Oficial de la Unión Europea dos nuevas Directivas relativas al régimen de garantía de los consumidores en los contratos de compraventa de bienes, incluidos los bienes con elementos digitales incorporados - Directiva (UE) 2019/771 ${ }^{1}$ (en adelante, Directiva de Compraventa de Bienes) - y en contratos de suministro de contenidos y servicios digitales - Directiva (UE) 2019/770² (en adelante, Directiva de Contenidos Digitales)-. ${ }^{3}$ Las recientes normas

\footnotetext{
${ }^{1}$ Directiva (UE) 2019/771 del Parlamento Europeo y del Consejo, de 20 de mayo de 2019, relativa a determinados aspectos de los contratos de compraventa de bienes, por la que se modifican el Reglamento (UE) n..$^{\circ}$ 2017/2394 y la Directiva 2009/22/ CE y se deroga la Directiva 1999/44/CE, DO L 136 de 22.5.2019, pp. 28-50.

${ }^{2}$ Directiva (UE) 2019/770 del Parlamento Europeo y del Consejo de 20 de mayo de 2019 relativa a determinados aspectos de los contratos de suministro de contenidos y servicios digitales, DO L 136 de 22.5.2019, pp.1-27.

${ }^{3}$ Para una evaluación general de ambas Directivas, véase K. SeIn y G. Spindler, "The new Directive on Contracts for the Supply of Digital Content and Digital Services - Scope of Application and Trader's Obligation to Supply - Part 1", European Review of Contract Law, no 3, 2019, pp. 257-279; K. SeIn y G. SPIndLeR, "The new Directive on Contracts for Supply of Digital Content and Digital Services - Conformity Criteria, Remedies and Modifications - Part 2", European Review of Contract Law, nº 4, 2019, pp. 365-391; J. StABentheiner, C. Wendehorst y B. Zöchling-Jud (Coord.), Das neue europäische Gewährleistungsrecht - Zu den Richtlinien (EU) 2019/771 über den Warenkauf sowie (EU) 2019/770 über digitale Inhalte und digitale Dienstleistungen, Wien, Manz Verlag, 2019; D. StaudenmaYer, "Auf dem Weg zum digitalen Privatrecht - Verträge über digitale Inhalte”, Neue Juristische Wochenschrift, n 35, 2019, pp. 2497-2501; B. ZöchlınG-Jud, "Das neue Europäische Gewährleistungsrecht für den Warenhandel", Zeitschrift für das Privatrecht der Europäischen Union, n 3, 2019, pp. 115-133 ; I. BACH, "Neue Richtlinien zum Verbrauchsgüterkauf und zu Verbraucherverträgen über digitale Inhalte", Neue Juristische Wochenschrift, $\mathrm{n}^{\circ}$ 24, 2019, pp. 1705-1711; J. Morais CARVALHo, "Sales of Goods and Supply of Digital Content and Digital
} 
comunitarias surgen en el contexto de la "Estrategia para un Mercado Único Digital" y de los esfuerzos de armonización de un "Derecho contractual europeo". ${ }^{4}$ La nueva Directiva de Compraventa cambia el tratamiento de la materia hasta ahora regulada por la Directiva 1999/44/CE, la cual queda derogada a partir del 1 de enero de 2022. ${ }^{5}$ Ambas directivas deben transponerse a la legislación nacional antes del 1 de julio de 2021 y ser aplicadas por los Estados miembros a partir del 1 de enero de $2022 .{ }^{6}$

2. Este artículo trata específicamente de los plazos para el efectivo ejercicio de las medidas correctoras por falta de conformidad según las dos nuevas Directivas (UE) 2019/770 y 2019/771; en particular, aborda tales plazos en caso de los vicios ocultos o redhibitorios, que solamente se detectan algún tiempo después de la entrega del respectivo bien o del suministro del contenido o servicio digital. El tema es relevante por lo menos por dos razones: primeramente, porque la efectividad de la medida correctora aplicable en caso de vicio oculto depende precisamente de que el consumidor disponga de tiempo suficiente para hacer valer sus derechos. $\mathrm{Si}$, por ejemplo, es usual en un determinado ordenamiento jurídico que ya hayan transcurrido los plazos de responsabilidad del vendedor o que ya haya prescrito el derecho del consumidor cuando los vicios ocultos se hacen aparentes, las medidas correctoras tienen poca o ninguna utilidad práctica. Es evidente, por consiguiente, que la evaluación de la solución legislativa presentada en las dos nuevas directivas, más específicamente, de la plena armonización de los regímenes de garantía buscada por estas directivas ${ }^{7}$, depende en gran medida de la armonización de los plazos para el efectivo ejercicio de las medidas correctoras.

3. En segundo lugar, un análisis de los plazos en caso de vicios ocultos reviste especial importancia en virtud de las características especiales de los contratos de suministro de contenidos y servicios digitales - o de la venta de bienes con elementos digitales incorporados -, ya que estos no suelen tener la estructura de una compraventa típica, en la que se cambian los bienes por un precio una sola vez. Más bien, la ejecución de esos contratos es a largo plazo, y a menudo se refieren a una obligación de suministro continuo de los contenidos o servicios digitales. Precisamente porque esos contratos suelen ejecutarse a largo de un período de tiempo, los requisitos para la conformidad no pueden relacionarse con un único marco temporal, sino que han de cumplirse durante un cierto período de tiempo que debe, a su vez, ser determinado por la ley. ${ }^{8}$ Dado que las dos directivas prevén estos contratos de "ejecución continua", en los cuales el vendedor de bienes con elementos digitales incorporados o el empresario de contenidos digitales se obligan al suministro continuo de los contenidos o servicios, se justifica el examen detallado de los plazos para el ejercicio de medidas correctoras en caso de vicios ocultos.

Services - Overview of Directives 2019/770 and 2019/771", Journal of European Consumer and Market Law, $\mathrm{n}^{\circ}$ 8, 2019, pp. 194-201. Acerca de las propuestas anteriores de la Comisión Europea, véase C. Wendehorst y B. Zöchling-Jud (Coord.), Ein neues Vertragsrecht für den digitalen Binnenmarkt? - Zu den Richtlinienvorschlägen der Europäischen Kommission vom Dezember 2015, Wien, Manz Verlag, 2016; M. ARTZ y B. Gsell (Coord.), Verbrauchervertragsrecht und digitaler Binnenmarkt, Tübingen, Mohr Siebeck, 2018; S. Grundmann (Coord.), European Contract Law in the Digital Age, Cambridge/Antwerp/Portland, Intersentia, 2018; B. FAUVARQUE-Cosson, The new proposal for harmonised rules for certain aspects concerning contracts for the supply of digital content (termination, modification of the digital content and right to terminate long term contracts), 2016; B. Gsell, "Europäischer Richtlinien-Entwurf für vollharmonisierte Mangelrechte beim Verbraucherkauf - Da capo bis zum Happy End?", Zeitschrift für europäisches Privatrecht, nº 3, 2018, pp. 501-506 ; F. Zoll, "The Remedies in the Proposals of the Online Sales Directive and the Directive on the Supply of Digital Content", Journal of European Consumer and Market Law, no 6, 2016, 6 EuCML pp. 250-254; y C. DegenefFe, "Defectos materiales y jurídicos en la propuesta de directiva de 2015 relativa a determinados aspectos de los contratos de compraventa en línea y otras ventas a distancia de bienes", Revista de Derecho Privado, no 5, 2017, pp. 29-68.

${ }^{4}$ M. GrÜNBERGER, "Verträge über digitale Güter”, Archiv für die civilistische Praxis, nº 218, 2018, pp. 218-222; además B. Gsell, "Rechtsbehelfe bei Vertragswidrigkeit in den Richtlinienvorschlägen zum Fernabsatz von Waren und zur Bereitstellung digitaler Inhalte", en M. ARTz y B. Gsell (Coords.), Verbrauchervertragsrecht und digitaler Binnenmarkt Tübingen, Mohr Siebeck, 2018, pp. 143-144.

${ }^{5}$ Art. 23 párr. $1^{\circ}$ Dir (UE) 2019/771.

${ }^{6}$ Art. 24 apdo. 1 Dir (UE) 2019/770 y art. 24 apdo. 1 Dir (UE) 2019/771.

${ }^{7}$ Véase especialmente III infra.

${ }^{8}$ Véase con respecto a los límites temporales art. 11 apdos. 2 y 3 , y además art. 8 apdos. 2 y 4, art. 12 apdos. 2,3 y 5 , art. 14 apdo. 5 párr. $2^{\circ}$, art. 16 apdo. 1 párr. $2^{\circ}$, y art. 19 apdo. 1 de la Dir (UE) 2019/770; también art. 10 apdo. 2, además art. 7 apdo. 3 y art. 11 apdo. 3 de la Dir (UE) 2019/771. 
4. A continuación, se compararán los diferentes plazos de las medidas correctoras en las dos directivas y, en particular, se discutirán las diferencias entre ellas. El objetivo es evaluar tanto la calidad de las respectivas soluciones legislativas como también la coherencia del concepto general. Sin embargo, en este artículo no se abordará la cuestión específica de la obligación del empresario o del vendedor de proporcionar actualizaciones al consumidor, la cual se encuentra, por cierto, prevista en las dos nuevas directivas. ${ }^{9}$

\section{Breves consideraciones sobre la delimitación del ámbito de aplicación objetivo de las directivas}

5. Como se verá más adelante ${ }^{10}$, hay diferencias entre los regímenes de garantía previstos en ambas directivas, por lo que se debe hacer algunas breves consideraciones de los límites de sus respectivos ámbitos de aplicación.

6. Las dos directivas deben complementarse mutuamente. ${ }^{11}$ La Directiva (UE) 2019/771 abarca, según su art. 3.1 en conjunto con el art. 2.1 a 2.3 y 2.5, los contratos de compraventa de bienes B2C. En principio quedan excluidos de su campo de aplicación los contratos con consumidores para el suministro de contenidos o servicios digitales. Estos están sometidos al régimen de la Directiva (UE) 2019/770. ${ }^{12}$ Sin embargo, la Directiva de Compraventa de Bienes establece en el art. $3.32^{\mathrm{a}}$ frase que sus disposiciones también deberán englobar los contenidos o servicios digitales que estén incorporados a los bienes y sean suministrados con ellos con arreglo al contrato de compraventa, con independencia si el suministro se realiza por el propio vendedor o por un tercero. ${ }^{13}$ Por lo tanto, hay dos requisitos que deben satisfacerse: en primer lugar, debe tratarse de un elemento digital incorporado al bien, tal como se define en el art. 2.5b, es decir, del elemento digital sin el cual el bien no puede realizar sus funciones. ${ }^{14}$ Además, la obligación de suministro del elemento digital debe derivar del contrato de compraventa. Este requisito puede ser un poco más problemático, dado que, conforme al Considerando $n^{\circ} 15$ Dir (UE) 2019/771, el legislador europeo pretendió abarcar tanto la disposición expresa de suministro del contenido digital en el contrato de compraventa como también la hipótesis de los "contratos de compraventa que puedan interpretarse de modo que comprendan el suministro de contenidos o servicios digitales específicos porque estos normalmente están incluidos en bienes del mismo tipo y el consumidor puede esperar razonablemente que lo estén dada la naturaleza de los bienes y teniendo en cuenta toda declaración pública realizada por el vendedor (...)". La dificultad de interpretación residirá, por tanto, en diferenciar, en el caso de que no exista una disposición expresa en el contrato, cuándo se trata de un solo contrato - es decir, la compraventa engloba también el suministro de los elementos digitales, aunque sea realizado por un tercero - y cuándo se trata de dos contratos, uno de compraventa, que está sujeto a la Dir 2019/771,

\footnotetext{
9 Véase Art. 7 apdos. 3 y 4 Dir (UE) 2019/771; y art. 8 apdos. 2 y 3 Dir (UE) 2019/770. Para el examen del tema, véase C. Wendehorst, "Aktualisierungen und andere digitale Dauerleistungen”, en J. STABentheiner, C. Wendehorst y B. ZöChLING-Jud (Coord.), Das neue europäische Gewährleistungsrecht - Zu den Richtlinien (EU) 2019/771 über den Warenkauf sowie (EU) 2019/770 über digitale Inhalte und digitale Dienstleistungen, Wien, Manz Verlag, 2019, pp. 111-139; y T. RIEHм у M.A. ABOLD, "Mangelgewährleistungspflichten des Anbieters digitaler Inhalte", Zeitschrift für Urheber- und Medienrecht, nº 2, 2018, pp. 86-87.

${ }^{10}$ Véase III 2 y 3; IV, V, VI y VII infra. Para otros puntos de divergencia, véase, por ej., A. MetzGer, "Verträge über digitale Inhalte und digitale Dienstleistungen: Neuer BGB-Vertragstypus oder punktuelle Reform”, Juristen Zeitung, n 12, 2019, pp. 578-579.

${ }^{11}$ Art. 3 apdo. 3 Dir (UE) 2019/771, art. 3 apdo. 4 Dir (UE) 2019/770; además, véase el Considerando no 13 Dir (UE) 2019/771 y el Considerando $n^{\circ} 20 \operatorname{Dir}($ UE) 2019/770.

${ }^{12}$ Art. 3 apdo. $31^{\text {a }}$ frase Dir (UE) 2019/771 y art. 3 apdos. 1 y $41^{\text {a }}$ frase Dir (UE) 2019/770.

${ }_{13}$ Para los debates del Consejo sobre si los elementos digitales incorporados deberían someterse al régimen de la Directiva de Contenidos Digitales, véase: D. STaudenmayer, en comentario al art. 3 Dir (UE) 2019/770, en R. Schulze y D. StaudenmayER (Coord.), EU Digital Law Article-by-Article Commentary, Baden-Baden, Nomos, 2020, nm. 75; además C. Kern, "Anwendungsbereich der Warenkauf- und der Digitale Inhalte-RL”, en J. STABentheiner, C. Wendehorst y B. Zöchling-Jud (Coord.), Das neue europäische Gewährleistungsrecht - Zu den Richtlinien (EU) 2019/771 über den Warenkauf sowie (EU) 2019/770 über digitale Inhalte und digitale Dienstleistungen, Wien, Manz Verlag, 2019, pp. 43-44.

${ }^{14}$ Véase también J. Morais Carvalho, "Contratos de Compraventa de Bienes (Directiva 2019/771) y Suministro de Contenidos o Servicios Digitales (Directiva 2019/770) - Ámbito de aplicación y grado de armonización”, Cuadernos de Derecho Transnacional, nº 1, 2020, pp. 936-937; y M. GRÜNBERGER, "Verträge...", op cit., pp. 285ss. sobre los "productos híbridos".
} 
y otro de suministro, que será regulado por la Dir $2019 / 770 .{ }^{15}$ La solución debe tener en cuenta las particularidades del caso concreto, a través de la interpretación del contenido del contrato celebrado entre las partes y objetivamente la naturaleza de los bienes vendidos. ${ }^{16}$ Aun así, el problema no se resolverá fácilmente. Al respecto, persiste cierta inseguridad jurídica, porque las partes contratantes que desconocen la aplicación de dos regímenes distintos de las directivas ni siquiera forman conscientemente la voluntad de concluir uno o dos contratos.

7. Sin embargo, la Directiva de Contenidos Digitales se aplica al soporte material que sirva exclusivamente como "portador de contenidos digitales"17. En este caso, el objeto principal del contrato es el suministro del contenido o servicio digital y el soporte material no es más que un instrumento para la transferencia de tales contenidos. Dicho con otras palabras: para la delimitación del régimen aplicable "no es el soporte de datos lo que hace que el software sea una cosa, sino el software el que hace que el soporte de datos sea un contenido digital." ${ }^{18}$ Puede pensarse, por poner un ejemplo, en un CD para la instalación de cierto software.

\section{Alcance de la plena armonización con respecto a los defectos ocultos}

\section{Adopción del principio de armonización plena por ambas directivas}

8. Como se ha señalado, el alcance de la armonización de los plazos de las medidas correctoras en caso de falta de conformidad desempeña un papel importante en la evaluación global del efecto armonizador de ambas Directivas en los ordenamientos jurídicos de los Estados miembros. Por lo tanto, es necesario hacer de antemano algunas observaciones generales sobre la intensidad de la efectiva armonización de ambas Directivas en lo que respecta a las medidas corretoras del consumidor, en particular, en caso de vicios ocultos.

9. A diferencia de la anterior Directiva de Compraventa ${ }^{19}$, que adoptó el principio de armonización mínima, las dos nuevas directivas ${ }^{20}$ se comprometieron con el principio de armonización plena. El objetivo es "facilitar a las empresas, especialmente a las pymes, ofrecer sus productos en otros Estados miembros ${ }^{21}$ " y simultáneamente "garantizar un alto nivel de protección de los consumidores". ${ }^{22}$

\section{Posibilidad de adopción de medidas correctoras nacionales adicionales con plazos nacionales específicos según la Dir (UE) 2019/771}

10. El ámbito de aplicación de la Directiva de Compraventa de Bienes está expresamente limitado de tal manera, que no "afectará a las normas nacionales que no sean específicas de los contratos con los consumidores, que establezcan acciones concretas para determinados tipos de vicios que no fueran

\footnotetext{
${ }^{15}$ K. TONNER, "Die EU-Warenkauf-Richtlinie: auf dem Wege zur Regelung langlebiger Waren mit digitalen Elementen", Verbraucher und Recht, $\mathrm{n}^{\circ}$ 10, 2019, pp. 363 y 368-369 critica el propio ejemplo dado por el legislador europeo. Veáse además B. ZÖCHLING-JUD, "Das neue Europäische...", op cit., pp. 118-119.

16 J. Morais Carvalho, "Contratos...", op cit., p. 937; y también con interesantes notas sobre el proceso legislativo: D. Staudenmayer, en comentario al art. 3 Dir (UE) 2019/770, en R. Schulze y D. Staudenmayer (Coord.), EU Digital, op cit., nm. 83ss.

17 Art. 3 apdo. 3 Dir (UE) 2019/770.

${ }^{18}$ I. BACH, "Neue Richtlinien...", op cit., p. 1706: “Nicht der Datenträger macht die Software zur Sache, sondern die Software den Datenträger zum digitalen Inhalt".

${ }^{19}$ Art. 8 apdo. 2 Dir 1999/44/CE.

${ }^{20}$ Art. 4 Dir (UE) 2019/770 y art. 4 Dir (UE) 2019/771.

${ }^{21}$ Véase, en particular, el Considerando no 10 Dir (UE) 2019/771.

${ }^{22}$ Véase, en particular, el Considerando no 5 Dir (UE) 2019/771.
} 
manifiestos en el momento en que se celebró el contrato de compraventa". ${ }^{23}$ En otras palabras: en virtud de la nueva Directiva de Compraventa de Bienes, los Estados miembros siguen teniendo libertad para establecer su propio régimen nacional de remedios para los vicios ocultos («vices cachés ») siempre que este no se limite a los contratos con consumidores. ${ }^{24}$ Esta cláusula de apertura contrasta evidentemente con el objetivo de la nueva Directiva de Compraventa de alcanzar la plena armonización, sobre todo si se tiene en cuenta que la responsabilidad del vendedor por una falta de conformidad se refiere en la gran mayoría de los casos a los defectos ocultos..$^{25}$

11. Los posibles requisitos y efectos de esos remedios nacionales específicos para los defectos ocultos no se determinan ni restringen en mayor medida en la Directiva de Compraventa de Bienes. Por lo tanto, hay que suponer que los Estados miembros también son libres de regular los plazos de esas medidas correctoras nacionales específicas para los vicios ocultos de la manera que deseen, como excepción a los plazos impuestos por la directiva.

12. Sin embargo, habida cuenta del effet utile que se pretende lograr con el régimen de medidas correctoras de la directiva, no debe interpretarse que la autorización de los Estados miembros para establecer remedios nacionales específicos en caso de los defectos ocultos sustituya a los remedios previstos en la propia directiva, sino que los Estados miembros sólo pueden conceder al consumidor remedios nacionales adicionales que complementen los ya estipulados en la directiva. Porque si, por el contrario, se imagina que los Estados miembros puedan restringir los remedios del consumidor previstos por la propia directiva, mediante la estipulación de otros remedios nacionales específicos en caso de los vicios ocultos con requisitos más estrictos o efectos jurídicos menos favorables al consumidor, entonces la nueva Directiva de Compraventa, aunque en general adopte el principio de armonización plena, no alcanzaría, en relación con los defectos ocultos, ni siquiera el estándar de armonización mínima de la antigua Directiva 1999/44/CE. La antigua Directiva de Compraventa al Consumidor no autorizaba a los Estados miembros a derogar su nivel mínimo de protección del consumidor en caso de defectos ocultos mediante remedios nacionales específicos. No puede suponerse que ese retroceso haya sido ahora querido por el legislador europeo. Así pues, al examinar los plazos de los remedios por falta de conformidad en lo que sigue, es importante aclarar que sólo se contemplan aquellos previstos en la propia Directiva de Compraventa de Bienes, y no cualquier otro remedio nacional específico para los vicios ocultos, cuyos plazos se rigen por la legislación nacional.

\section{3. ¿Posibilidad de medidas correctoras nacionales adicionales con plazos nacionales específicos también según la Directiva (UE) 2019/770?}

13. A diferencia de la Directiva de Compraventa de Bienes ${ }^{26}$, las disposiciones de la Directiva de Contenidos Digitales no contienen una cláusula de apertura nacional que permita remedios naciona-

\footnotetext{
${ }^{23}$ Véase art. 3 apdo. 7 Dir (UE) 2019/771 y también Considerando $n^{\circ} 18$. Cabe señalar que el Considerando $\mathrm{n}^{\mathrm{o}} 18$ de la versión española de la Dir (UE) 2019/771 fue redactado de modo sustancialmente diverso de la cláusula de apertura introducida en el art. 3.7. Mientras que el art. 3.7, $2^{\mathrm{a}}$ frase, establece que la Directiva no afecta las normas nacionales "que no sean específicas de los contratos con los consumidores, que establezcan acciones concretas" para vicios ocultos, el Considerando $\mathrm{n}^{\mathrm{o}} 18$, a su vez, establecía que la Directiva no debería afectar normas nacionales "que no se refieran específicamente a los contratos con consumidores $\underline{n i}$ establezcan acciones" para vicios ocultos. Así pues, a contrario, según la redacción original del Considerando $\mathrm{n}^{\circ} 18$, la Directiva afectaría a las normas nacionales que contuviesen remedios nacionales específicos en caso de vicios ocultos. El error se corrigió en noviembre de 2019, conforme al DO L 305 de 26.11.2019, pp. 65-67. Se ha enmendado el Considerando $\mathrm{n}^{\circ} 18$ para disponer que la Directiva no debe afectar a las normas nacionales "que no se refieran específicamente a los contratos con consumidores $\underline{y}$ establezcan acciones concretas" para vicios ocultos.

${ }^{24}$ Además, según esta disposición, los Estados miembros siguen pudiendo establecer excepciones a la jerarquía de remedios de la Directiva de Compraventa de Bienes en lo que respecta a la falta de conformidad, que se manifiesta en un plazo de 30 días a partir de la entrega; en el mismo sentido, véase el Considerando ${ }^{\circ} 19$.

${ }^{25}$ Para una valoración crítica, véase B. Gsell, "Europäischer Richtlinien-Entwurf...”, op cit, pp. 501-506.

${ }^{26}$ Véase nota al pie n ${ }^{\circ} 23$ supra.
} 
les específicos en caso de vicios ocultos. Sin embargo, el Considerando $\mathrm{n}^{\circ} 12$ señala que "las normas nacionales que no se refieran específicamente a los contratos con consumidores $\mathrm{y}^{27}$ establezcan acciones concretas a causa de determinados tipos de vicios que no fueran manifiestos en el momento en que se celebró el contrato, a saber, disposiciones nacionales que puedan establecer normas específicas relativas a la responsabilidad del empresario por vicios ocultos", no deben ser afectadas por la Directiva de Contenidos Digitales. ${ }^{28}$ Esta afirmación legislativa es sorprendente. A falta de una cláusula de apertura comparable a la contenida en el art. 3.7 de la nueva Directiva de Compraventa de Bienes, se podría decir que, según la Directiva de Contenidos Digitales, las medidas correctoras nacionales específicas para los defectos ocultos son incompatibles con el art. 4, en la medida en que se desvían del régimen de medidas correctoras establecido en la Directiva. Además, la cláusula de apertura del art. 3.10 de la Directiva de Contenidos Digitales no puede considerarse como una base para tales remedios nacionales específicos. Esto es válido independientemente de si tales remedios con arreglo al Derecho nacional derivan del Derecho contractual general o no. Esta cláusula de apertura sólo abarca los aspectos del Derecho contractual en general "en tanto en cuanto no estén reguladas en la presente Directiva", mientras que las medidas correctoras por falta de conformidad, incluidos en los casos de defectos ocultos, sí están regulados en la directiva. De lo contrario, esto significaría que los Estados miembros estarían generalmente autorizados a burlar el régimen de remedios establecido en la directiva, mediante las correspondientes normas nacionales fundadas únicamente en el Derecho general de los contratos.

14. Además, la nueva Directiva de Compraventa de Bienes también contiene una cláusula de apertura para aspectos del Derecho contractual en general. ${ }^{29}$ Aún así el legislador europeo consideró necesario crear una cláusula especial de apertura para el caso de los defectos ocultos. Esto también demuestra que los remedios específicos para los vicios redhibitorios no están contemplados en la cláusula de apertura del Derecho contractual general en la Directiva de Contenidos Digitales. ${ }^{30}$ Nos parece que la contradicción entre el Considerando ${ }^{\circ} 12$ y el texto de las disposiciones de la Directiva de Contenidos Digitales y, más específicamente, el art. 4, debe ser resuelta en el espíritu de esta última. Los "Considerandos" de una directiva no tienen un efecto regulador en sí mismos de forma aislada, sino que sólo sirven para aclarar y explicar las disposiciones de la Directiva. ${ }^{31}$ Por lo tanto, a diferencia de la situación prevista en la Directiva de Compraventa de Bienes, se debe considerar que los Estados miembros no tienen derecho a prever remedios específicos para los defectos ocultos cuyos plazos - o otros requisitos y efectos jurídicos - difieran de los de la Directiva de Contenidos Digitales.

15. Sin embargo, dado que el derecho de los Estados miembros a remedios nacionales específicos para los defectos ocultos sólo autorizaría, en cualquier caso, remedios adicionales, pero no la restric-

\footnotetext{
${ }^{27}$ Como ya se ha señalado en la nota al pie $n^{\circ} 23$ supra en relación con el Considerando $n^{\circ} 18$ del Dir (UE) 2019/771, el Considerando $n^{\circ} 12$ de la versión española de la Dir (UE) 2019/770 también establecía que la Directiva no debería afectar normas nacionales "que no se refieran específicamente a los contratos con consumidores $\underline{n i}$ establezcan acciones" para vicios ocultos. Aquí también ha sido corregido el error (véase: DO L 305 de 26.11.2019, pp. 62-64).

${ }^{28}$ Véase también ya B. Gsell, en comentario al art. 14 Dir (UE) 2019/770, en R. Schulze y D. Staudenmayer (Coord.), EU Digital Law - Article-by-Article Commentary, Baden-Baden, Nomos, 2020, nm. 76.

${ }^{29}$ Art. 3 apdo. 6 Dir (UE) 2019/771.

${ }^{30}$ Para una posición divergente, véase D. Staudenmayer, en comentario al art. 3 Dir (UE) 2019/770, en R. Schulze y D. Staudenmayer (Coord.), EU Digital, op cit., nm. 156; J. Morais Carvalho, "Contratos...", op cit., p. 933 y nota al pie n ${ }^{\circ}$ 19; y, de forma general, M. ZINNER, "Was vom CESL übrigblieb - Neues Verbrauchervertragsrecht mit digitalem Einschlag", Verbraucher und Recht, $\mathrm{n}^{\mathrm{o}}$ 7, 2019, pp. 241-242.

${ }^{31}$ Además, en virtud de las disposiciones del Considerando no 14 Dir (UE) 2019/770, se podría suponer que, en lo que respecta a falta de conformidad debida a una force majeure o a impedimentos similares que escapan al control del empresario, los Estados miembros tienen plena libertad para determinar las consecuencias de dicha falta de conformidad. Pero, una vez más, las disposiciones de la directiva en sí no contienen una cláusula de apertura nacional correspondiente y, por lo tanto, no se puede considerar que los Estados miembros tengan derecho a desviarse del régimen de remedios de la directiva, incluso en lo que respecta a los casos de force majeure o impedimentos similares que escapen al control del empresario, véase también: B. Gsell, en comentario al art. 14 Dir (UE) 2019/770, en R. Schulze y D. StaudenmaYer (Coord.), EU Digital, op cit., nm. 76. Y también, en general sobre el mero valor interpretativo de la Exposición de Motivos: C. FuenteseCa Degeneffe, "Defectos materiales...", op cit., p. 34.
} 
ción del régimen de remedios de la directiva ${ }^{32} ; \mathrm{y}$ dado que sólo se considerarán los remedios previstos en la directiva a continuación, las dudas sobre la interpretación del Considerando $\mathrm{n}^{\circ} 12$ son irrelevantes para lo que sigue.

\section{Plazos de responsabilidad}

16. En primer lugar, se abordará la cuestión de los períodos de responsabilidad ${ }^{33}$ del vendedor $o$ del empresario en las dos nuevas directivas, durante los cuales debe producirse o manifestarse la falta de conformidad, para que el consumidor tenga derecho a exigir las medidas correctoras.

\section{Directiva de Compraventa de Bienes (UE) 2019/771}

\section{A) Bienes}

17. En lo que se refiere a los bienes, hay dos requisitos de tiempo que deben tenerse en cuenta tanto en la nueva como en la anterior Directiva de Compraventa de Bienes: en primer lugar, el bien debe estar libre de vicios en el momento de la entrega. ${ }^{34}$ En otras palabras, el vendedor es responsable de cualquier falta de conformidad que exista en el momento de la entrega ${ }^{35}$ En segundo lugar, él sólo será responsable de dicha falta de conformidad si esta se manifiesta en el plazo de dos años a partir de la entrega. ${ }^{36}$ Por lo tanto, hay aquí una distinción bien definida entre el período para que se produzca la falta de conformidad y el período para que esta se manifieste. Lo mismo no sucede, como veremos más adelante, en relación con los bienes con elementos digitales incorporados cuando hay una obligación de suministro continuo de este contenido o servicio digital.

18. Tanto con arreglo a la antigua como a la nueva Directiva de Compraventa de Bienes, los Estados miembros podrán mantener o adoptar plazos de responsabilidad más largos. ${ }^{37}$ La adopción de un plazo estricto de dos años ha encontrado resistencia en el Parlamento Europeo, dado que muchos Estados miembros ya prevén plazos más largos en sus respectivos sistemas jurídicos nacionales y una reducción obligatoria significaría para ellos una disminución significativa del nivel de protección ya arraigado en sus ordenamientos jurídicos. ${ }^{38}$ Contrariamente a lo que establecía la Propuesta de la Directiva relativa a Contratos de Compraventa a Distancia ${ }^{39}$, se ha mantenido la flexibilidad en relación con regímenes de garantía más beneficiosos para los consumidores. Así pues, se ha derogado de hecho

\footnotetext{
${ }^{32}$ Véase III.2 supra.

${ }^{33}$ Para una distinción entre la plazo de responsabilidad del vendedor y plazo de prescripción, véase art. 5.1 Directiva 1999/44/CE y STJUE 13.7.2017 (Ferenschild, C-133/16). Además véase, entre otros, B. GsELL, "Kapitel L: Verbraucherschutz", en J. von Staudingers Kommentar zum Bürgerlichen Gesetzbuch mit Einführungsgesetz und Nebengesetzen - Eckpfeiler des Zivilrechts, $6^{\text {a }}$ ed. revisada, Berlin, Sellier/DeGruyter, 2018, nm. 70; P. BYDLINSKI, "Verbrauchsgüterkauf-RL: Unterscheidung zwischen Haftungsdauer und Verjährungsfrist; Verkürzung der Verjährungsfrist unter zwei Jahre auch bei gebrauchten Gütern unzulässig", Juristische Blätter, no 9, 2017, pp. 569-573; U. KulKe, "Verbrauchsgüterkauf: Die vertragliche Begrenzung der Verkäuferhaftung auf unter zwei Jahre", Monatsschrift für Deutsches Recht, $\mathrm{n}^{\circ}$ 17, 2018, pp. 1025-1031, especialmente pp. 1025-1026; y D. LEENEN, "Die Richtlinienwidrigkeit der Verkürzung der Verjährungsfrist beim Verbrauchsgüterkauf über gebrauchte Sachen", Juristen Zeitung, nº 6, 2018, pp. 284-291, especialmente p. 285.

${ }^{34}$ Art. 10 apdo. 1 Dir (UE) 2019/771 y art. 2 apdo. 1 Dir (UE)1999/44/CE.

${ }^{35}$ Sobre las normas relativas a la carga de la prueba, véase VII infra.

${ }^{36}$ Art. 10 apdo. 1 Dir (UE) 2019/771 y art. 5 apdo. 1 Dir (UE) 1999/44/CE.

${ }^{37}$ Art. 10 apdo. 3 Dir (UE) 2019/771.

${ }^{38}$ El hecho de que los Estados miembros con regímenes más generosos peleen políticamente por las cláusulas de apertura nacionales es un fenómeno frecuente cuando se elaboran directivas de plena armonización y a menudo limita considerablemente sus efectos armonizadores, véase a este respecto B. GseLL, "Europäischer Richtlinien-Entwurf... op cit., pp. 501-506; B. GseLL y H. M. Schellhase, "Vollharmonisiertes Verbraucherkreditrecht - Ein Vorbild für die weitere europäische Angleichung des Verbrauchervertragsrechts?", Juristen Zeitung, no 1, 2009, pp. 20-29; y K. TonNER, “Die EU-Warenkauf-Richtlinie...”, op cit., p. 364.

${ }^{39}$ Art. 3 de la Propuesta de Directiva del Parlamento Europeo y del Consejo relativa a determinados aspectos de los contratos de compraventa en línea y otras ventas a distancia de bienes COM (2015) 635 final.
} 
en parte el principio de la plena armonización, que no obstante sigue en principio la directiva, como se ha señalado anteriormente ${ }^{40}$. La situación jurídica se mantiene a este respecto concretamente igual que la de la antigua Directiva de Compraventa, que seguía el principio de la armonización mínima. ${ }^{41}$ Por una parte, la flexibilidad de los Estados miembros para establecer plazos más largos sirve al propósito de una mayor protección del consumidor, ya que aquellos Estados que prevén plazos más largos de responsabilidad del vendedor en sus ordenamientos jurídicos podrán así mantenerlos, en beneficio de los consumidores. Por otra parte, sin embargo, a causa de esta "fragmentación jurídica" permitida por la flexibilidad de plazos más largos, no se logra alcanzar el objetivo de la plena armonización que pretende la directiva, es decir, la superación de "los obstáculos relacionados con el Derecho contractual con que se encuentran las compraventas transfronterizas de bienes en la Unión". ${ }^{42}$

\section{B) Bienes con elementos digitales incorporados}

19. Ya se ha señalado que, por regla general, la Directiva de Compraventa de Bienes no se aplica a los contratos de suministro de contenidos o servicios digitales. ${ }^{43}$ Estos están sujetos al régimen de responsabilidad de la Directiva de Contenidos Digitales, a lo que nos referiremos más adelante. ${ }^{44}$ Sin embargo, las disposiciones de la Directiva de Compraventa contemplan los denominados "bienes con elementos digitales" -los cuales requieren un contenido o servicio digital para desempeñar sus funciones-, siempre que los elementos digitales "se suministren con los bienes con arreglo al contrato de compraventa, con independencia de si dichos contenidos o servicios digitales son suministrados por el vendedor o por un tercero" 45 . En este caso, el régimen de responsabilidad del vendedor descrito anteriormente, según el cual el período mínimo de responsabilidad por la falta de conformidad es de dos años a partir del momento de la entrega, también se aplica según el art. $10.12^{\mathrm{a}}$ frase, en principio, a los vicios de los elementos digitales incorporados al bien. El tema exige un examen más profundo en relación con los elementos digitales que deban suministrarse de forma continua.

\section{a) Plazo de responsabilidad distinto con respecto al suministro continuo de contenidos o servicios digitales}

20. En lo que se refiere a estos bienes con elementos digitales, la nueva Directiva de Compraventa de Bienes distingue entre los contratos que prevén un único acto de suministro de contenidos o servicios digitales -o mismo una serie de actos individuales de suministro-, por una parte, y entre los contratos que prevén el suministro de contenidos o servicios digitales de forma continua a lo largo de un período de tiempo, por otra. ${ }^{46}$ Aquellos están sujetos a las reglas generales del art. 10.1, como hemos indicado ya. Las reglas especiales del art. 10.2 sólo se aplican a esta última constelación de bienes con

\footnotetext{
${ }^{40}$ Véase III.1 y nota al pie ${ }^{\circ} 20$ supra.

${ }^{41}$ Véase III.1 y nota al pie n ${ }^{\circ} 19$ supra.

${ }^{42}$ Véase, con respecto a este propósito legislativo, en particular el Considerando $\mathrm{n}^{\mathrm{o}} 7$, así como los Considerandos $\mathrm{n}^{\mathrm{0}} 6 \mathrm{y}$ siguientes de la Dir (UE) 2019/771. También críticos: B. Gsell, "Europäischer Richtlinien-Entwurf... op cit., pp. 501-506; T. KuPfer y J. Weiss, "Die Warenkaufrichtlinie - Schlussstein in der Harmonisierung des kaufrechtlichen Gewährleistungsrechts?", Verbraucher und Recht, no 3, 2020, p. 100; M. ZINNER, "Was vom CESL...", op cit., p. 241. Para una posición divergente, véase K. TonNER, "Die EU-Warenkauf-Richtlinie...", op cit., p. 364, que entiende que deben ser los Estados miembros con plazos más cortos - como es el caso de Alemania, por ej. - que deben considerar la posibilidad de seguir la tendencia de adoptar plazos más largos en favor de los consumidores, y no el contrario.

${ }^{43}$ Véase II supra y Art. 3 apdo. 3 Dir (UE) 2019/771.

${ }^{44}$ Véase IV.2 infra.

${ }^{45}$ Art. 3 apdo. 3 en conjuto con art. 2 apdo. 5 (b) Dir (UE) 2019/771.

46 Véase también: D. STAUdenMaYer, "Kauf von Waren mit digitalen Elementen - Die Richtlinie zum Warenkauf", Neue Juristische Wochenschrift, n’ 35, 2019, p. 2892. Además, como señala R. Schulze, "Die Digitale-Inhalte-Richtlinie - Innovation und Kontinuität im europäischen Vertragsrecht", Zeitschrift für Europäisches Privatrecht, nº 4, 2019, p. 717, la atribución de consecuencias jurídicas distintas en diversos contextos confiere a esta diferenciación entre un único acto de suministro y el suministro continuo un papel central en el nuevo Derecho contractual de los contenidos y servicios digitales.
} 
elementos digitales, es decir, cuando el contrato de compraventa prevé el suministro continuo de contenidos o de servicios digitales a lo largo de un período de tiempo.

21. En tales casos, hay dos posibilidades según el art. 10.2: (i) si el contrato prevé el suministro continuo durante un período de tiempo de hasta dos años, el plazo de responsabilidad del vendedor por cualquier falta de conformidad de los contenidos o servicios digitales será de dos años a partir de la entrega; (ii) a su vez, si el contrato prevé el suministro continuo durante más de dos años, el vendedor será responsable durante todo el período de suministro previsto en el contrato. Si, por ejemplo, el vendedor de un reloj inteligente se compromete a prestar un determinado servicio digital para este reloj de forma continua durante tres años, será responsable de cualquier falta de conformidad de estos servicios digitales durante todo el período contractual de tres años. A continuación, se abordará el problema de la ausencia de una distinción clara, en relación con estos contratos de suministro continuo, entre el plazo para que se produzca el defecto y el plazo para que este se manifieste.

\section{b) Ausencia de un plazo para que el defecto oculto que se haya "producido" a tiempo se vuelva aparente}

22. En este contexto, es necesario realizar una breve valoración de este régimen con diferentes períodos de responsabilidad del vendedor en caso de bienes con elementos digitales, cuando, por un lado, el contenido o servicio digital debe suministrarse en uno acto o en una serie de actos individuales; y, por otro, cuando el suministro se efectúa de forma continua durante un período de tiempo. Como se indicó anteriormente ${ }^{47}$, debido al carácter permanente de la obligación, en último caso, es evidente que, a diferencia de lo que ocurre en una entrega única de bienes sin elementos digitales -o mismo cuando hay un solo acto de suministro de servicios digitales-, el período de responsabilidad del vendedor por vicios ocultos no puede relacionarse con un único marco temporal. Debido a esta peculiaridad se justifica el tratamiento jurídico distinto del período de responsabilidad del vendedor a los casos en que el contrato de compraventa establezca una obligación de suministro continuo de contenidos o servicios digitales.

23. Sin embargo, hay una diferencia de trato entre los períodos de responsabilidad en la nueva Directiva de Compraventa que no parece estar totalmente justificada. Mientras que en el caso de los bienes sin elementos digitales o cuyos elementos digitales deban suministrarse en un solo acto o en una serie de actos individuales de suministro, se distingue entre el momento en que los bienes deben estar en conformidad, es decir, en el momento de la entrega, y el período de tiempo en que debe manifestarse el defecto para justificar la responsabilidad del vendedor, no hay esta diferenciación en el caso de los bienes con elementos digitales, cuyos servicios o contenidos digitales deban suministrarse de forma continua. Para estos, sólo hay un único período de responsabilidad del vendedor. La responsabilidad no se limita a las situaciones en que un defecto inicial se manifiesta más tarde, sino que se extiende a los casos en que un defecto no estaba presente inicialmente, pero que se produjo después de la entrega. Así, para que el vendedor sea responsable del vicio oculto, es suficiente que la falta de conformidad "se produzca o se manifieste" ${ }^{" 48}$ dentro del plazo de suministro.

24. Esta disposición es particularmente problemática en relación con los vicios que se produz$\operatorname{can}^{49}$ durante el período de dos años o el período de suministro contractual respectivo, si es más amplio,

\footnotetext{
${ }^{47}$ Véase I supra.

48 Ver Art. 10 apdo. 2 Dir (UE) 2019/771.

49 Véase también, por ejemplo, la redacción de las versiones inglesa, francesa, italiana, portuguesa y alemana del art. 10 apdo. 2 Dir (UE) 2019/771: “... lack of conformity of the digital content or digital service that occurs or becomes apparent..."; “...défaut de conformité du contenu numérique ou du service numérique qui survient ou apparaît..."; “...difetto di conformità del contenuto digitale o del servizio digitale che si verifica o si manifesta...”; "... falta de conformidade do conteúdo ou serviço digital que ocorra ou se manifeste..."; y “...Vertragswidrigkeit des digitalen Inhalts oder der digitalen Dienstleistung, die (...) eintritt oder offenbar wird...".
} 
pero que no se manifiestan inmediatamente. Dado que es suficiente que la falta de conformidad ocurra dentro de este período para generar la responsabilidad del vendedor, el régimen jurídico adoptado por la directiva no proporciona un límite de tiempo para que los defectos de los contenidos digitales que se produjeron a tiempo se hagan aparentes. Así pues, en el caso de tales defectos ocultos que solamente se manifiestan una vez transcurrido el plazo contractual de suministro correspondiente, la responsabilidad del vendedor por los contenidos y servicios digitales incorporados que deban suministrarse de forma continua podrá ser considerablemente mayor que la responsabilidad del vendedor por el propio bien, así como por los contenidos y servicios digitales incorporados que deban suministrarse en un solo acto. ${ }^{50}$

25. Volvamos al ejemplo anterior de la compraventa de un reloj, pero con la siguiente variación: si, al cabo de tres años, el comprador de un reloj tradicional descubre que el mecanismo de relojería ya era defectuoso en el momento de la entrega, no puede recurrir a ninguna medida correctora en virtud de la nueva Directiva de Compraventa, porque el plazo de dos años para que el vicio oculto se haga evidente ya ha expirado. ${ }^{51} \mathrm{Si}$, por otro lado, el comprador de un reloj inteligente, a quién se le prometió en el contrato de compraventa el procesamiento ininterrumpido de datos personalizados de aptitud física durante dos años, se entera, al cabo de tres años, a través de información relevante de los medios de comunicación, de que una de las características de este programa no funcionó correctamente durante el período de vigencia del contrato, podrá recurrir a las medidas correctoras con arreglo a la nueva Directiva de Compraventa, a pesar de que hayan transcurrido más de dos años desde que se produjo el defecto. ${ }^{52}$

26. Entendemos que habría sido más coherente con el período de responsabilidad de dos años, generalmente aplicable a los bienes, si la Directiva de Compraventa de Bienes hubiera estipulado que, incluso en el caso de suministro continuo de contenidos o servicios digitales, un defecto debe manifestarse siempre en un plazo de dos años a partir de su aparición o, respectivamente, en un período de suministro contractual más largo, para dar lugar a responsabilidad del vendedor. La fijación de un plazo para que los defectos se hagan evidentes no sólo promueve la seguridad jurídica, sino también la protección uniforme del consumidor en los sistemas jurídicos de los Estados Miembros, objetivos ambos que la directiva intentaba alcanzar.

27. Sin embargo, cabe mencionar que el problema de los defectos ocultos en el caso de suministro continuo de los contenidos y servicios digitales se ve mitigado en parte por la propia directiva. Como veremos más adelante, se permite a los Estados miembros, dentro de ciertos límites establecidos en los arts. 10.4 y 10.5, restringir el ejercicio efectivo de las medidas correctoras por los consumidores mediante fijación de períodos de prescripción nacionales. ${ }^{53}$

\section{Directiva de Contenidos y Servicios Digitales (UE) 2019/770}

28. A continuación, se abordará el período de responsabilidad del empresario por la falta de conformidad del suministro de contenidos o servicios digitales en virtud de la Directiva (UE) 2019/770. La Directiva de Contenidos Digitales, al igual que la nueva Directiva de Compraventa de Bienes, establece

${ }^{50}$ De manera diferente, B. Zöchling-Jud, "Das neue Europäische...", op cit. p. 131, entiende que la falta de conformidad debe manifestarse durante el período de suministro del contenido digital: "Diese Frist [Haftungsfrist] ist durch die Richtlinie vorgegeben: (...) bei fortlaufender Bereitstellungspflicht digitaler Inhalte oder Dienstleistungen haftet der Verkäufer, wenn die Vertragswidrigkeit in dem Zeitraum offenbar wird, über den sich der Verkäufer zur Bereitstellung verpflichtet hat (Art. $10 \mathrm{Abs}$. 2)". Sin embargo, como ya se ha señalado, para que el vendedor sea responsable basta con que el defecto se produzca durante el período de suministro, pero no que se haga necesariamente evidente.

${ }^{51}$ Sólo si un Estado miembro ha hecho uso de la "cláusula de apertura" en favor de una legislación nacional más favorable a los consumidores (art. 10 apdo. 3 Dir (UE) 2019/771) y así ha estipulado un período más largo de responsabilidad, el vendedor seguirá siendo responsable más allá del plazo de dos años.

${ }_{52}$ Art. 10 apdo. 2 Dir (UE) 2019/771.

${ }^{53}$ Véase V.1 infra. 
una distinción entre los contratos que prevén un único acto de suministro o mismo una serie de actos individuales de suministro, por una parte, y los contratos que prevén el suministro continuo durante cierto período de tiempo, por otra. Examinemos cada uno de ellos.

\section{A) Un solo acto de suministro o una serie de actos individuales de suministro}

29. En lo que se refiere al primer conjunto de supuestos, es decir, los contratos que prevén un único acto de suministro o una serie de actos individuales de suministro, cabría esperar que la Directiva de Contenidos y Servicios Digitales, al igual que a la Directiva de Compraventa ${ }^{54}$, también impusiera un período de responsabilidad de dos años, el cual englobara todos los defectos que se manifiesten a partir del momento del suministro. Sin embargo, la Directiva de Contenidos Digitales sólo exige que el comerciante sea responsable de todos los defectos existentes en el momento del suministro, sin fijar un plazo para que aquellos se hagan evidentes. ${ }^{55}$ Por otro lado, empero, la directiva establece que cuando un Estado miembro fije un período de tiempo para que la falta de conformidad se manifieste, dicho período no podrá ser inferior a dos años a partir del momento del suministro respectivo, ${ }^{56}$ estableciendo así una nueva cláusula de apertura que debilita la plena armonización pretendida. ${ }^{57}$

30. Cabe preguntarse si, a este respecto, hay una diferencia sustancial entre las dos directivas. La respuesta es que probablemente no. Si se considera que las disposiciones de una directiva europea no tienen, en ningún caso, un efecto directo horizontal sobre la relación entre las partes privadas contratantes ${ }^{58}$, sino que deben transponerse al Derecho nacional de los Estados miembros, entonces la diferencia entre ambas directivas es probablemente de carácter puramente técnico. El contenido de ambos regímenes en las dos directivas es que los Estados miembros deben garantizar que el empresario o el vendedor sea al menos responsable de las faltas de conformidad que se manifiesten en un plazo de dos años a partir del momento del suministro o de la entrega, respectivamente. Además, ambas directivas también son coherentes en el sentido de que permiten a los Estados miembros imponer períodos de responsabilidad más generosos en favor del consumidor. ${ }^{59}$ Esta coherencia debe reconocerse independientemente del hecho de que, como ya se ha mencionado ${ }^{60}$, la mera armonización mínima en este sentido pone en peligro el objetivo legislativo de eliminar las diferencias entre los ordenamientos jurídicos de los Estados miembros.

\section{B) Suministro continuo a lo largo de un período de tiempo}

31. A diferencia del tratamiento de los supuestos de suministro continuo de contenidos o servicios digitales en la Directiva de Compraventa, la Directiva de Contenidos y Servicios Digitales no prevé un período mínimo de responsabilidad de dos años del empresario, sino que simplemente estipula que él será responsable de cualquier falta de conformidad "que se produzca o se manifieste dentro del período durante el cual deben suministrarse los contenidos o servicios digitales con arreglo al contrato" ${ }^{61}$

\footnotetext{
${ }^{54}$ Art. 10 apdo. 1 Dir (UE) 2019/771.

${ }_{55}$ Art. 11 apdo. 2 párr. 1 Dir (UE) 2019/770.

${ }^{56}$ Art. 11 apdo. 2 párr. 2 Dir (UE) 2019/770.

${ }^{57}$ Véase, además: D. StaudenmaYer, “Auf dem Weg...”, op cit., p. 2500.

${ }_{58}$ Véase la respectiva jurisprudencia reiterada del TJEU, por ej., en la STJCE 26.2.1986 (Marshall, C152/84); STJCE 14.7.1994 (Faccini Dori, C91/92); STJEU 19.1.2010 (Kücükdeveci, C555/07); y STJEU 24.1.2012 (Dominguez, C282/2010).

${ }^{59}$ Véase IV.1 y notas al pie $\mathrm{n}^{\circ} 37$ y 56 supra.

${ }^{60}$ Véase IV.1 y nota al pie ${ }^{\circ} 38,42$ y 57.

${ }^{61}$ Art. 11 apdo. 3 Dir (EU) 2019/770. D. Staudenmayer, “Kauf von Waren...”, op cit., p. 2893, señala con razón que en la Directiva de Compraventa la fijación de un período de responsabilidad mínimo de dos años para los elementos digitales incorporados a los bienes se justifica, en la medida en que esos elementos digitales son, per definitionem, esenciales para el funcionamiento de los bienes al cual están incorporados. Así pues, establecer un período de responsabilidad de menos de dos años para los vicios de los elementos digitales podría significar en última instancia un acortamiento de facto del período de garantía de dos años del bien.
} 
32. Así, por ejemplo, si un contrato estipula el suministro continuo de ciertos contenidos de audio y el consumidor descubre, al cabo de tres años, que algún contenido no estaba disponible durante el período de vigencia del contrato, la presente Directiva no limita el ejercicio de una medida correctora contra el empresario a un período de tiempo para que la falta de conformidad se manifieste.

33. Una vez más, esto puede criticarse, ya que los vicios ocultos que se manifiestan tardíamente se tratan de forma diferente, dependiendo de si el contrato prevé un único acto de suministro o un suministro continuo, sin que exista una justificación objetiva suficiente para esta diferencia de trato ${ }^{62}$ Del mismo modo que se criticó el tratamiento del suministro continuo de contenidos y servicios digitales en bienes con elementos digitales incorporados en la Directiva de Compraventa, también aquí hubiera sido más coherente que la Directiva de Contenidos y Servicios Digitales exigiera que el defecto se manifestase en un plazo de dos años o eventualmente en un plazo más largo, si el contrato estipulase el suministro del contenido o servicio digital por más de dos años.

\section{Resumen}

34. Respecto a los bienes con elementos digitales y a los contenidos o servicios digitales que deban suministrarse en un solo acto o en una serie de actos individuales de suministro, el vendedor o el empresario será responsable de los defectos que existían en el momento de la entrega o del acto de suministro, si se manifiestan en un plazo de dos años a partir de la entrega o del acto de suministro respectivo.

35. Por el contrario, según ambas directivas, los contenidos y los servicios digitales que deban suministrarse de forma continua han de estar libres de defectos a lo largo de toda la duración del contrato de suministro, sin que ningún plazo europeo limite las medidas correctoras en favor del consumidor debido a defectos ocultos que se hayan producido dentro del plazo de dos años o del plazo del suministro previsto en el contrato -si es más largo-, pero que sólo hayan se manifestado después del período contractual de suministro respectivo.

\section{Plazos de prescripción}

36. A continuación, es necesario examinar en qué medida las reglas de prescripción -es decir, los plazos, durante los cuales el consumidor debe ejercer efectivamente sus derechos ${ }^{63}$ - contenidas en las dos directivas modifican el tratamiento de los períodos de responsabilidad. Cabe señalar, en primer lugar, que ninguna de las directivas establece un plazo de prescripción como tal. Las directivas tampoco regulan en general cuándo empiezan a correr los plazos de prescripción nacionales, cuánto tiempo pueden durar y cuándo terminan. Más bien, se limitan a estipular que los plazos de prescripción no pueden ser tan cortos que reduzcan ilícitamente el plazo de responsabilidad europeo respectivo. Veamos, sin embargo, lo que eso significa concretamente.

\section{Bienes y bienes con elementos digitales incorporados en la Directiva de Compraventa}

\section{A) Combinación del período de responsabilidad y del plazo de prescripción}

37. La Directiva de Compraventa se ocupa en el art. 10.4 Directiva (UE) 2019/771 de los plazos de prescripción que se aplican además del plazo de responsabilidad. Imagínese, por ejemplo, que determinada legislación nacional adopta el período mínimo de responsabilidad europeo de dos años y,

\footnotetext{
${ }^{62}$ B. Gsell, "Rechtsbehelfe...", op cit., p. 169, especialmente nota al pie n ${ }^{\circ} 111$.

${ }^{63}$ En lo que respecta a la distinción entre los períodos de responsabilidad y de prescripción, véase la nota al pie $\mathrm{n}^{\circ} 33$ supra.
} 
además, impone un plazo de prescripción. En este caso, el art. 10.4 Directiva (UE) 2019/771 establece que el plazo de prescripción nacional debe ser lo suficientemente largo como para permitir al consumidor efectivamente exigir las medidas correctoras por los defectos que se han hecho evidentes dentro del período de responsabilidad europeo respectivo.

38. Esto significa que el plazo de prescripción nacional debe ser: (i) razonablemente más largo que el plazo de responsabilidad europeo, a fin de que el consumidor pueda ejercer efectivamente medidas correctoras en los casos de defectos que se manifiesten hasta el último día del período de responsabilidad $^{64}$; o (ii) si es más corto, no debe empezar a transcurrir tan pronto que no se observe el período mínimo de dos años desde la entrega para que el defecto se haga evidente, de conformidad con los art. $10.1,10.2$ y 10.4 Directiva (UE) 2019/771. ${ }^{65}$

39. Volvamos también al ejemplo de la venta de un reloj tradicional y imaginemos que el comprador sólo descubre que el mecanismo es defectuoso 22 meses después de la entrega. Si la legislación nacional estipula que el plazo de prescripción empieza a correr en el momento de la entrega del reloj, independientemente del conocimiento del consumidor sobre el defecto, entonces no habrá ningún problema en este caso, mientras que el plazo de prescripción sea considerablemente más largo que el plazo de responsabilidad europeo, por ejemplo, de tres años. En este caso, el consumidor dispondría de tiempo suficiente para enjuiciar la demanda, incluso si el defecto sólo se descubriera al final del período de responsabilidad europeo de dos años. Si, por el contrario, el plazo de prescripción nacional fuera sólo de un año, entonces ya habría transcurrido en el momento en que se descubrió el defecto, incluso si el defecto se hubiera manifestado dentro del plazo de responsabilidad europeo de dos años. Eso es exactamente lo que el art. 10.4 Dir 2019/771 prohíbe.

40. En otras palabras, si los defectos se descubren a tiempo dentro del plazo de responsabilidad europeo, el consumidor debe poder exigir las medidas correctoras, sin que el legislador nacional reduzca el plazo de responsabilidad europeo mediante un plazo de prescripción más corto o que ya haya caducado en el momento en que se descubrió el defecto.

\section{B) Plazo de prescripción sin adopción de un período de responsabilidad}

41. La situación es básicamente la misma si un Estado miembro no adopta explícitamente el período de responsabilidad europeo, sino que sólo establece un período de prescripción, lo que está permitido para los Estados en el art. 10.5 Dir (UE) 2019/771. Volvamos al ejemplo de la venta del reloj y imaginemos que la legislación nacional sólo prescribe un plazo de prescripción de un año. En este caso, el inicio del plazo de prescripción nacional debe ser tal que el vendedor sea efectivamente responsable de cualquier falta de conformidad que salga a la luz dentro del plazo de responsabilidad europeo de dos años. En este ejemplo, el plazo de prescripción de un año no podría empezar a correr desde el momento de la entrega, ya que esto impediría al consumidor recurrir a las medidas correctoras en caso de un defecto que se hubiera manifestado sólo un año después de la entrega, pero dentro del plazo de responsabilidad europeo de dos años.

${ }^{64}$ Así pues, en Alemania, por ej., será necesario enmendar el $\S 438$ apdo. 1 no 3, apdo 2 BGB, que prevé un plazo de prescripción de exactamente dos años a partir de la entrega.

${ }^{65}$ En lo mismo sentido: I. BACH, "Neue Richtlinien...", op cit., p. 1708; B. Gsell, en comentario al art. 14 Dir (UE) 2019/770, en R. Schulze y D. Staudenmayer (Coord.), EU Digital, op cit., nm. 17; y F.M. Corvo López, "Estudio de Derecho Comparado sobre las garantías en la venta de bienes de consumo en España y Portugal a la luz de la Directiva (EU) 2019/771", Cuadernos de Derecho Transnacional, $\mathrm{n}^{\circ}$ 1, 2020, p. 159; veáse también la opinión contraria de B. ZöCHLING-Jud, "Das neue Europäische...", op cit. p. 132, que considera admisible que un plazo de prescripción nacional se termine el mismo día que el plazo de responsabilidad: "Es ist daher m.E. zulässig, dass die Mitgliedstaaten eine Verjährungsfrist von zwei Jahren ab Lieferung der Ware vorsehen, auch wenn dann im Extremfall (Mangel wird erst am letzten Tag der zweijährigen Haftungsfrist offenbar) der Verbraucher faktisch nicht mehr in der Lage sein wird, seine Ansprüche auch durchzusetzen". 
42. En resumen, puede decirse que la Directiva de Compraventa de Bienes limita los plazos de prescripción nacionales de tal forma que el consumidor siempre pueda recurrir a las medidas correctoras en relación con los defectos que se encuentran dentro del plazo de responsabilidad europeo, que, por regla general, es de dos años. En otras palabras, el plazo de dos años de responsabilidad europeo no puede, por regla general, reducirse mediante plazos de prescripción nacionales.

\section{C) Bienes con elementos digitales que deban suministrarse de forma continua}

43. No obstante, la Directiva de Compraventa de Bienes permite en un supuesto el acortamiento del período de responsabilidad europeo - es decir, del límite de tiempo para que la falta de conformidad se haga evidente- por medio de plazos de prescripción nacionales. Este es el caso de los vicios ocultos en bienes con elementos digitales de suministro continuo. Como se mencionó anteriormente ${ }^{66}$, para que el vendedor sea responsable del vicio de los contenidos o servicios digitales según el art. 10.2, es suficiente que el defecto "se produzca $o$ se manifieste" a lo largo del período de responsabilidad. Por consiguiente, si el defecto se produce dentro del período de suministro establecido en el contrato, pero sólo se hace evidente mucho tiempo después, el consumidor aún puede seguir exigiendo medidas correctoras del vendedor. En este caso, la directiva no establece un límite de tiempo para que el vicio oculto se haga evidente.

45. Volvamos una vez más al ejemplo del comprador de un reloj inteligente, a quien se le prometió en el contrato de compraventa el procesamiento ininterrumpido de datos personalizados de aptitud física durante dos años, y que sólo después de tres años descubre que una de las características de este programa no funcionó correctamente durante el período de vigencia del contrato. Como ya se ha señalado, el comprador puede ejercer las medidas correctoras debido a la falta de conformidad, incluso si han transcurrido más de dos años desde que se produjo el defecto. En lo que se refiere a esta situación con arreglo a la Directiva de Compraventa de Bienes, el defecto sólo debe haberse producido en el plazo de dos años, independientemente del momento en que se hace evidente.

46. Precisamente en este contexto la Directiva de Compraventa permite a los Estados miembros, mediante plazos de prescripción nacionales, establecer un límite de tiempo para que los defectos que se hayan producido durante el período de suministro contractual se hagan evidentes. Sin embargo, la redacción de las disposiciones exige atención. El art. 10 en sus apartados 4 y 5, los cuales prohíben a los Estados miembros restringir el plazo de responsabilidad europeo establecido en los apartados 1 y 2 mediante plazos de prescripción nacionales ${ }^{67}$, se limita a exigir que los consumidores puedan ejercer las medidas correctoras con respecto a los defectos que se hayan manifestado dentro del plazo de responsabilidad europeo: “(...) los Estados miembros velarán por que dicho plazo de prescripción permita a los consumidores exigir las medidas correctoras (...) por cualquier falta de conformidad de la que sea responsable el vendedor con arreglo a los apartados 1 y 2 del presente artículo y que se manifieste dentro del plazo indicado en dichos apartados". Así pues, a contrario, los apartados 4 y 5 del art. 10 no exigen que los Estados miembros garanticen que los consumidores puedan ejercer eficazmente las medidas correctoras por un defecto que se haya producido dentro del período de responsabilidad europeo, pero que se haya manifestado sólo después de ese período. En resumen, se puede decir que, en lo que respecta a los bienes con elementos digitales que deban suministrarse de forma continua, la Directiva de Compraventa de Bienes permite a los Estados miembros reducir la responsabilidad del vendedor por los defectos ocultos que sólo se descubren una vez transcurrido el período de responsabilidad europeo ${ }^{68}$

66 Véase IV.1.B supra.

6710 apdos. 4 y 5 Dir (UE) 2019/771.

68 Sin embargo, si el ejemplo anterior se cambia en el sentido de que el procesamiento ininterrumpido de datos personalizados de aptitud física se prometió durante cuatro años, entonces, según el Art. 10.4 y 10.5, el Estado miembro no puede imponer un plazo de prescripción inferior a cuatro años $\mathrm{y}$, en consecuencia, el consumidor siempre puede ejercer medidas 
47. Así, por ejemplo, un Estado miembro es libre de imponer un plazo de prescripción de dos años, para el caso de contenidos digitales de suministro continuo conectados a un reloj inteligente, que se inicia a partir de la entrega y sólo se suspende si el defecto sale a la luz dentro de ese plazo. En resumen, puede decirse que, en lo que se refiere a los elementos digitales que deban suministrarse continuamente, la Directiva de Compraventa permite a los Estados miembros reducir la responsabilidad del vendedor por defectos ocultos que sólo se descubren una vez transcurrido el período de responsabilidad europeo.

48. Por una parte, esta facultad de los Estados miembros de promulgar los respectivos plazos de prescripción es razonable, ya que impide que la responsabilidad del vendedor dure muchos años más allá de los plazos de responsabilidad de la Directiva. Sin embargo, por otra parte, para lograr el objetivo de la armonización europea, habría sido preferible que el legislador europeo hubiera estipulado en la propia Directiva que un defecto siempre debe manifestarse dentro del período de responsabilidad para el ejercicio de medidas correctoras.

\section{Directiva de Contenidos Digitales}

49. Si examinamos hasta qué punto la Directiva de Contenidos Digitales permite que el período de responsabilidad europeo se reduzca mediante plazos de prescripción nacionales, el resultado es en parte sorprendente.

\section{A) Contenidos o servicios digitales que deban suministrase en un solo acto o en una serie de actos individuales}

50. En lo que se refiere a los contenidos o servicios digitales que deban suministrarse a los consumidores mediante un único acto o mediante una serie de actos individuales de suministro, los Estados miembros deben, de conformidad con la Directiva de Compraventa de bienes también bajo el régimen de la Directiva de Contenidos Digitales ${ }^{69}$, velar por que un plazo de prescripción nacional no pueda configurarse de tal manera que se impida al consumidor ejercer las medidas correctoras para subsanar defectos que se hayan manifestado dentro del plazo (mínimo) de responsabilidad europeo de 2 años, conforme al art. $10.22^{\circ}$ párr. Directiva 2019/770.

\section{B) Contenidos o servicios digitales que deben suministrarse de forma continua}

51. Sin embargo, en lo que se refiere a la situación de los contenidos o servicios digitales que deban suministrarse de forma continua, existe una diferencia con respecto a la Directiva de Compraventa de Bienes. Como se mencionó anteriormente ${ }^{70}$, la Directiva de Compraventa de Bienes permite a los Estados miembros mediante introducción de plazos de prescripción nacionales reducir la responsabilidad del vendedor por defectos ocultos que sólo se descubren una vez transcurrido el período de responsabilidad europeo. En otras palabras, con arreglo a la Directiva de Compraventa, los plazos de prescripción nacionales sólo se regulan a nivel europeo en el sentido de que no pueden restringir el ejercicio de las medidas correctoras por falta de conformidad que se haya manifestado durante el plazo del art. 10.2 Directiva (UE) 2019/771.

correctoras, incluso en el caso de defectos que se produjeron muy pronto pero que sólo se manifestaron tarde durante la vigencia del contrato. Véase también: K. SeIn y G. SPIndLer, "The new Directive...Part 2", op cit., pp. 385-386, en relacion con la Directiva de Contenidos Digitales.

${ }^{69}$ Art. 11 apdo. 2 párr. 3 Dir (UE) 2019/770.

${ }^{70}$ Véase V.1 supra. 
52. Por el contrario, en la Directiva de Contenidos Digitales ${ }^{71}$ se ha redactado la disposición correspondiente de tal manera que los plazos de prescripción nacionales deben permitir a los consumidores ejercer medidas correctoras tanto con respecto a las faltas de conformidad que se manifiesten durante el período de responsabilidad como a las faltas de conformidad que se produzcan durante su vigencia, pero que se manifiesten sólo después de transcurrido dicho período. ${ }^{72} \mathrm{Si}$ esta redacción se entiende literalmente, el consumidor debe poder ejercer efectivamente sus derechos con respecto a cualquier defecto que se produzca durante el periodo de suministro establecido en el contrato. Así, por ejemplo, si el consumidor fuera informado cinco años después de la finalización del plazo de suministro contractual de que se había producido un defecto oculto durante la vigencia del contrato, su derecho a las medidas correctoras no podría ser limitado por un plazo de prescripción nacional. Por lo tanto, la legislación nacional en materia de prescripción debería siempre garantizar que el plazo de prescripción nacional sólo pueda expirar después de que se descubra un defecto que se produjo durante el período de responsabilidad.

53. Se puede dudar de que el legislador europeo haya querido realmente una restricción tan amplia de los plazos de prescripción nacionales. Tal restricción no parece apropiada, sobre todo teniendo en cuenta el régimen divergente de la Directiva de Compraventa de Bienes. Así pues, no es sorprendente que el Considerando ${ }^{\circ} 58$ de la Directiva de Contenidos Digitales establezca explícitamente que la legislación nacional debe impedir un plazo de prescripción que imposibilite el ejercicio de medidas correctoras para los defectos que se hayan manifestado durante el período de responsabilidad, mientras que no menciona los defectos que se produjeron dentro de ese período pero que sólo se hicieron evidentes después. Por lo tanto, parece necesario interpretar la limitación al legislador nacional en la Directiva de Contenidos Digitales en contra de su redacción y en el sentido más restrictivo del Considerando ${ }^{\circ} 58$.

54. Sin embargo, sólo una decisión del TJEU podrá aclarar la situación de forma definitiva. Hasta que eso suceda, seguirá existiendo cierta inseguridad jurídica.

\section{Resumen}

55. Tanto la Directiva de Compraventa de Bienes como la Directiva de Contenidos Digitales impiden que el legislador nacional establezca plazos de prescripción nacionales que reduzcan el ejercicio de las medidas correctoras por el consumidor por defectos que se hayan manifestado antes de que haya transcurrido el período de responsabilidad. Sin embargo, en lo que se refiere a los contenidos o servicios digitales que deben suministrarse de forma continua, sigue siendo dudoso en virtud de la Directiva de Contenidos Digitales en qué medida el legislador nacional está autorizado por medio de los plazos de prescripción a reducir el ejercicio efectivo de las medidas correctoras para los defectos que se produjeron dentro del período contractual de suministro respectivo pero que no se manifestaron hasta después de transcurrido de dicho período. A continuación, conviene mencionar brevemente otras dos distinciones entre las dos directivas en lo que respecta a los plazos de las medidas correctoras del consumidor.

\footnotetext{
${ }^{71}$ Art. 11 apdo. 3 párr. 2 Dir (UE) 2019/770: "Si, con arreglo al Derecho nacional, los derechos previstos en el artículo 14 también están sujetos o solo están sujetos a un plazo de prescripción, los Estados miembros velarán por que dicho plazo de prescripción permita a los consumidores exigir las medidas correctoras establecidas en el artículo 14 por cualquier falta de conformidad que se produzca o se manifieste durante el período indicado en el párrafo primero."

${ }^{72}$ Véase, en general, también la crítica de K. Sein y G. SpindLer, “The new Directive...Part 2", op cit., pp. 385-386, en relación con los vicios que se manifiestan mientras el contrato sigue vigente. Además, F. ZoLl, en comentario al art. 11 Dir (UE) 2019/770, en R. Schulze y D. Staudenmayer (Coord.), EU Digital Law Article-by-Article Commentary, Baden-Baden, Nomos, 2020, nm. 37, también critica la disposición, pero considera que el plazo de prescripción podría comenzar ya desde el final del contrato de suministro.
} 


\section{Obligación de informar}

56. Al igual que la Directiva 1999/44/CE ${ }^{73}$, la nueva Directiva de Compraventa de Bienes permite a los Estados miembros supeditar los derechos del consumidor a una notificación al vendedor de la falta de conformidad en un plazo mínimo de dos meses a partir de la fecha en que el consumidor la haya detectado. ${ }^{74}$ Aunque el art. 12 emplee la nomenclatura "obligación" de informar lato sensu-también en la versión portuguesa "obrigação" de informar-, se trata en realidad de una carga ${ }^{75}$ que incumbe al consumidor -en portugués, de un "ônus jurídico"- ${ }^{76} \mathrm{El}$ incumplimiento de esta exigencia de comportamiento supondrá, en la forma prevista en la directiva, la pérdida de un derecho en perjuicio del propio consumidor, es decir, la posibilidad de ejercer las medidas correctoras por falta de conformidad: “(...) para poder hacer valer sus derechos (...)". ${ }^{77}$ Cabe señalar que, a diferencia de los sistemas jurídicos portugués y español ${ }^{78}$, por ejemplo, el Derecho alemán no prevé tal carga de información, y tampoco se espera que, debido a su mantenimiento en la nueva Directiva de Compraventa de Bienes, el legislador alemán ahora la introduzca en perjuicio del consumidor. ${ }^{79}$

57. Una vez más, la directiva prevé una cláusula de apertura que posibilita el tratamiento substancialmente distinto de la materia en los Ordenamientos jurídicos nacionales de los Estados miembros. El incumplimiento de la carga de información, al menos en los derechos de la mayoría de los Estados miembros que hacen uso de esta norma, tiene consecuencias jurídicas rigurosas para el consumidor y afecta precisamente a la posibilidad de un ejercicio efectivo de las medidas correctoras. En consecuencia, la opción de adoptar una cláusula de apertura en este ámbito contribuye a que sigan existiendo diferentes niveles de protección del consumidor en los sistemas jurídicos de los Estados miembros. Así pues, también aquí se puede constatar que la Directiva de Compraventa de Bienes no logra su objetivo autoimpuesto ${ }^{80}$ de armonizar de manera plena las reglas de garantía en los contratos de compraventa de bienes. ${ }^{81}$

58. Por el contrario, la Directiva sobre Suministro de Contenidos y Servicios Digitales no contiene una disposición similar y su undécimo considerando afirma explícitamente que los Estados miembros no pueden introducir tal obligación de informar. La diferencia de trato entre las dos directivas es históricamente comprensible, pero difícilmente puede justificarse.

\footnotetext{
${ }^{73}$ Véase art. 5.2 Dir 1999/44/CE.

${ }_{74}$ Art. 12 Dir (UE) 2019/771.

${ }^{75}$ En español también se puede encontrar el término "deberes de cumplimento", como en la traducción de la obra de K. Larenz, Derecho Civil - Parte General, traducción de M. Izquierdo y M. Picavea, Editorial Revista de Derecho Privado, 1978, p. 266, que trata de las llamadas "Obliegenheiten"; o también "deberes de menor intensidad". A su vez, la versión alemana de la Directiva de Compraventa utiliza en el art. 12 la nomenclatura "Rügeobliegenheit".

${ }^{76}$ Con respecto a la distinción véase, entre otros: M. Wolf y J. Neuner, Allgemeiner Teil des Bürgerlichen Rechts, $11^{\mathrm{a}}$ ed., München, C.H. Beck, 2019, pp. 225-227; además sobre la distinción entre "obrigação", "dever” y "ônus" en portugués: A. Varela, Das Obrigações em Geral, vol. I, 6ª ed., Coimbra, Almedina, 1989, pp. 51 y ss, especialmente pp. 56-57, para la definición de "ônus jurídico"; y E.R. Grau, "Nota sobre a Distinção entre Obrigação, Dever e Ônus", Revista da Faculdade de Direito da Universidade de São Paulo, no 77, 1982, pp. 177-183.

77 Art. 12 Dir (UE) 2019/771. Sin embargo, se hace notar que la transposición en España de la norma análoga contenida en el art. 5.2 de la Dir 1999/44/CE estableció, de manera diferente, que el incumplimento del plazo de dos meses "no supondrá la pérdida del derecho al saneamiento", sino que el consumidor es responsable "de los daños o perjuicios efectivamente ocasionados por el retraso en la comunicación" (art. 123 apdo. 5 de la Ley General para la Defensa de los Consumidores y Usuarios).

78 F.M. Corvo López, "Estudio de Derecho...", op cit., pp. 157ss.

${ }^{79}$ I. BACH, "Neue Richtlinien...", op cit., p. 1708.

${ }^{80}$ Véase III.1 supra.

${ }^{81}$ También son críticos de esta disposición: I. BACH, "Neue Richtlinien...", op cit., p. 1705 y 1708; T. KuPfer y J. WeISS, "Die Warenkaufrichtlinie...", op cit., p. 100; D. STAUdenMAYER, "Kauf...”, op cit., p. 2893, que describe la obligación de informar como verdadeiro defecto de nacimiento ("Geburtsfehler") de la antigua Directiva 1999/44/CE que ahora se mantiene en la nueva Directiva de Compraventa; y, en general, M. ZINNER, "Was vom CESL...,", op cit., p. 241.
} 


\section{Carga de la prueba}

59. Con relación a los bienes sin elementos digitales y a los bienes con elementos digitales incorporados que se suministren en un único acto de suministro, como ya hemos visto ${ }^{82}$, el vendedor será responsable de la falta de conformidad que exista en el momento de la entrega (art. 10.1 Directiva (UE) 2019/771). Igual que la Directiva 1999/44/CE, la nueva Directiva de Compraventa de Bienes también prevé una presunción iuris tantum ${ }^{83}$ a favor del consumidor, de que la falta de conformidad ya existía en el momento de la entrega ${ }^{84} \mathrm{La}$ inversión de la carga de la prueba tiene por finalidad no sólo proteger al consumidor, sino que promover mayor rapidez y facilidad del comercio a gran escala en favor del propio vendedor, ya que el consumidor, en menor medida, considera necesario el examen minucioso del producto que adquiere. ${ }^{85}$

60. Sin embargo, mientras que en la antigua directiva la inversión de la carga de la prueba sólo se aplicaba en el caso de los defectos que se manifestaban en un plazo de seis meses a partir de la entrega, en art. 11.1 de la nueva Directiva (UE) 2019/771 este plazo se extendió a un año, con la posibilidad de que los Estados miembros, según el art. 11.2 Directiva (UE) 2019/771, lo amplíen a dos años. La directiva anterior también permitía una prórroga del plazo, durante el cual el defecto debía manifestarse, ya que estaba dirigida únicamente a una armonización mínima. ${ }^{86}$ No obstante, el mantenimiento en la nueva directiva de una cláusula de apertura con respecto a la inversión de la carga de la prueba, cuya relevancia práctica es enorme,${ }^{87}$ ya que tiene un efecto directo sobre el resultado de las demandas, fragiliza el objetivo de la directiva de armonizar los sistema de garantías en los sistemas jurídicos de los Estados miembros. ${ }^{88}$

61. Por su parte, la Propuesta de la Comisión ${ }^{89}$ intentó establecer un período de presunción aún más largo, de dos años, lo que, por cierto, ya se ha adoptado en algunos ordenamientos jurídicos europeos, como en Portugal y Francia, por ejemplo..$^{90}$ La Propuesta pretendía igualmente impedir la

\footnotetext{
${ }^{82}$ Véase IV.1 supra.

${ }^{83}$ Art. 11 apdo. $12^{\mathrm{a}}$ parte Dir (UE) 2019/771. No considera necesaria la previsión expresa de la posibilidad de prueba en contra: B. Zöchling-Jud, "Das neue Europäische...”, op cit., p. 125.

${ }^{84}$ Art. 5 apdo. 3 Dir 1999/44/CE. Sobre la extensión de la presunción también a los defectos posteriores a la entrega, en el sentido de que se derivan de otra falta de conformidad que ya estaba presente en el momento de la entrega ("Grundmangel”), véase STJUE 4.6.2015 (Faber, C-497/13) y los comentarios sobre la STJUE (Anmerkung zu EuGH Urt. v. 4.6.2015 C-497/13) entre otros, de B. Gsell, "Beweislastumkehr zugunsten des Verbraucher-Käufers auch bei nur potenziellem Grundmangel - Besprechung von EuGH, Urt. v. 04.06.2015, Rs. C-497/13 - Faber”, Verbraucher und Recht, n 12, 2015, pp. 446ss.; S. LORENZ, en Fachdienst Zivilrecht - LMK, n ${ }^{\circ}$ 6, 2015, 370162; L. HüBNER, en Neue Juristische Wochenschrift, $\mathrm{n}^{\circ}$ 31, 2015, p. 2241; P. Rотт, en Europäische Zeitschrift für Wirtschaftsrecht, n 14, 2015, pp. 560-561; S. HeINEMEYER, en Zeitschrift für das Privatrecht der Europäischen Union, no 4, 2015, pp.179-182.

${ }^{85}$ Como señala F. Maultzsch, "Der Ausschluss der Beweislastumkehr gem. § 476 BGB”, Neue Juristische Wochenschrift, $\mathrm{n}^{\mathrm{o}}$ 43, 2006, pp. 3092-3093, en la venta de bienes a los consumidores, la prioridad es la rapidez de las transacciones, que el vendedor "compra" para sí mismo a través de una regla desfavorable de la carga de la prueba: "[.] bei Verbrauchergeschäften [hat] der schnelle Warenabsatz Priorität, den der Verkäufer durch die für ihn ungünstige Beweislastregelung (...) quasi erkauft". En el mismo sentido S. LoRENZ, en comentario al § 477 BGB, en Münchner Kommentar zum Bürgerlichen Gesetzbuch, vol. 8, $8^{\mathrm{a}}$ ed., München, C. H. Beck, 2019, nm. 4.

${ }^{86}$ Véase III.1 y nota al pie n ${ }^{\circ} 19$ supra.

${ }^{87}$ El $§ 477$ BGB (anteriormente $§ 476$ BGB) es una de las disposiciones más controvertidas y de mayor importancia práctica del Derecho de obligaciones moderno, como ya se afirmó en B. Gsell, "Sachmangelbegriff und Reichweite der Beweislastumkehr beim Verbrauchsgüterkauf", Juristen Zeitung, no 1, 2008, pp. 29ss.

${ }^{88}$ También críticos, M. ZINNER, "Was vom CESL....", op cit., p. 241; I. BACH, “Neue Richtlinien...”, op cit., p. 1708, que afirma que no se logrará la plena armonización en uno dos aspectos centrales de la protección del consumidor. Cabe recordar que la propia Propuesta consideraba que la armonización del plazo de inversión de la carga de la prueba es esencial para garantizar la seguridad jurídica en la Unión. Véase a respecto el Considerando no 26 COM (2015) 635 final: "Con el fin de que las empresas puedan basarse en un conjunto único de normas en el toda la Unión, es necesario armonizar plenamente el plazo durante el cual la carga de la prueba de la falta de conformidad se invierte a favor del consumidor".

${ }^{89}$ Art. 8 apdo. 3 COM (2015) 635 final.

${ }^{90}$ Art. 3 apdo 2 DL n $^{\circ} 67 / 2003$ establece que las faltas de conformidad relativas a los bienes muebles que se manifiesten en el plazo de dos años "presumem-se existentes já nessa data". Alemania y España, por otra parte, deberán modificar las normas
} 
introducción de un plazo nacional diferente, independientemente de que fuera más o menos ventajoso al consumidor. ${ }^{91}$ Sin embargo, esta regla no se mantuvo durante el proceso legislativo, y el legislador europeo optó finalmente por un período mínimo de un año, junto con la cláusula de apertura del art. 11.2.

62. De todos modos, se plantea ahora la cuestión de cómo debe valorarse esta duplicación del período de la inversión de la carga de la prueba de seis meses a un año. En parte de la literatura ya se expresaban preocupaciones con respecto a la ampliación del plazo de presunción después de que la Comisión presentara su propuesta, en particular debido al temor de que los consumidores abusaran de los recursos por falta de conformidad. ${ }^{92}$ No creemos que haya razón para temer que, con la duplicación del plazo, los consumidores traten a los bienes de forma más descuidada y así exijan medidas correctoras del vendedor, también cuando el defecto haya sido causado por una manipulación indebida de los bienes por parte del propio consumidor. No hay que olvidar que el consumidor sigue soportando el encargo de enjuiciar la demanda contra el vendedor, si este no pone "voluntariamente" los bienes en conformidad a requerimiento del consumidor. Por lo tanto, es probable que la mayoría de los consumidores no haga nada ante el rechazo del vendedor. ${ }^{93}$ Además, con arreglo al estudio empírico encargado por la Comisión Europea en 2015 $5^{94}$, la distinción que se hacía en la antigua Directiva de Compraventa en dos plazos diferentes - uno de seis meses para la inversión de la carga de la prueba, y el otro de dos años para la garantía de los bienes- no era bien comprendida por los consumidores y por las empresas. En consecuencia, los empresarios a menudo ya habrían ampliado de facto la inversión de la carga de la prueba a todo el período de garantía de dos años. ${ }^{95}$

63. En principio, se aplicará el mismo régimen a los bienes con elementos digitales, es decir, que las faltas de conformidad que se manifiesten en el plazo de un año a partir del acto de suministro se presumirá que han existido desde esa fecha. Sin embargo, también en este caso existen diferencias de trato con respecto al suministro continuo de elementos digitales. En relación con este supuesto, el art. 11.3 Directiva (UE) 2019/771 establece que la carga de la prueba de cualquier defecto que se manifieste dentro del período de responsabilidad de dos años o de un período contractual de suministro más largo recae en el vendedor.

64. La Directiva de Contenidos Digitales prevé una distinción similar. En el caso de los defectos de los contenidos y servicios digitales que deban suministrarse en un solo acto o en una serie de actos individuales de suministro, la carga de la prueba recaerá según el art. 12.2 Directiva (UE) 2019/770 también en el empresario, siempre que la falta de conformidad se manifieste en el plazo de un año a partir de la fecha del suministro respectivo. Sin embargo, de acuerdo con la Directiva de Contenidos Digitales, los Estados miembros no pueden ampliar este período de un año.

sobre el tema en el $§ 477$ del BGB y el art. 123 apdo. 1 par. 2 de la Ley General para la Defensa de los Consumidores y Usuarios, respectivamente, para adaptarse al período de un año previsto en la nueva Directiva.

${ }^{91}$ Para una valoración de la Propuesta de la Comisión, véase B. Gsell, "Rechtsbehelfe...", op cit., pp. 164-165; y C. FUenteseCa Degeneffe, "Defectos materiales...", op cit., pp. 64 ss.

92 Véase, por ej., N. HärTING y P. Gössling, "Online-Kauf in der EU - Harmonisierung des Kaufgewährleistungsrechts", Computer und Recht, $\mathrm{n}^{\circ}$ 3, 2016, pp. 168-169; F. MAultzsch, "Der Entwurf für eine EU-Richtlinie über den Online-Warenhandel undandere Formen des Fernabsatzes von Waren", Juristen Zeitung, $\mathrm{n}^{\circ}$ 5, 2016, p. 242; y T. STARIRADEFF, "Auswirkungen des Richtlinienentwurfs auf den Online-Handel”, Zeitschrift für IT-Recht und Recht der Digitalisierung, n 11, 2016, p. 717, que considera que la regla perjudica desproporcionadamente a los vendedores, porque cuanto más tiempo pasa después de la entrega de las mercancías, más importante es la manipulación de las mismas por parte del consumidor para su estado.

${ }^{93}$ Véase ya B. Gsell, "Rechtsbehelfe...", op cit., p. 164 ss; evalúa positivamente el aumento del término, bajo el aspecto de la protección del consumidor D. STAUDENMAYER, "Kauf von Waren...", op cit., p. 2893; y también, en general, en relación con la Directiva de Contenidos Digitales A. MetzGer, "Verträge...", op cit., p. 581.

${ }^{94}$ Consumer market study on the functioning of legal and commercial guarantees for consumers in the EU, Final report, Luxembourg: Publications Office of the European Union, 2015, en 4.2.4, pp. 57ss. y 8.1.2 p. 221.

${ }_{95}$ Consumer market..., op cit., en 8.1.2, p. 221. 
65. En lo que se refiere a los contenidos y servicios digitales que deban suministrarse de forma continua, de conformidad con el art. 12.3 Dir (UE) 2019/770, el empresario asume la carga de la prueba de cualquier defecto que se manifieste durante el período de suministro contractual respectivo. ${ }^{96}$

66. Esta imposición más amplia de la carga de la prueba al vendedor y al empresario en los casos de suministro continuo de contenidos y servicios digitales en ambas Directivas tiene su lógica. A diferencia de lo que ocurre cuando hay una sola entrega de un bien al consumidor, en el caso del suministro continuo no puede decirse que el contenido o servicio digital abandone de una vez por todas la esfera de influencia del empresario y que, a partir de la entrega, sólo esté sujeto a la esfera de influencia del consumidor. Precisamente esta diferencia entre los dos contratos justifica la imposición general de la carga de la prueba al vendedor o empresario a lo largo del período de suministro establecido en el contrato.

\section{Conclusión}

67. En una evaluación global, puede decirse que ambas directivas, en principio, regulan de forma adecuada los plazos de las medidas correctoras disponibles para los consumidores en caso de falta de conformidad. No obstante, persisten diferencias entre las dos directivas, en particular en lo que se refiere a la obligación de informar, al derecho de los Estados miembros a establecer plazos de prescripción nacionales para reducir el plazo de responsabilidad europeo y a la atribución al empresario de la carga de la prueba. Esas diferencias no parecen estar plenamente justificadas y dan lugar a un tratamiento diferenciado de los vicios ocultos en las dos directivas.

68. En definitiva, el efecto armonizador de los plazos en ambas directivas es considerablemente limitado, ya que sólo estipulan períodos mínimos de responsabilidad del vendedor o del empresario y permiten a los Estados miembros mantener o introducir plazos más largos. Además, las cláusulas de apertura en relación con la obligación de informar, la carga de la prueba y la posibilidad de un régimen adicional para los defectos ocultos («vices cachés») en la Directiva de Compraventa también introducen fragilidad en el objetivo de la armonización.

${ }^{96}$ Crítico de la necesidad de la presunción en el caso de suministro continuo: F. Zoll, en comentario al art. 12 Dir (UE) 2019/770, en R. Schulze y D. Staudenmayer (Coord.), EU Digital Law Article-by-Article Commentary, Baden-Baden, Nomos, 2020, nm. 20 y 33. 